\title{
Topology-optimized slow-light couplers for ring-shaped photonic crystal waveguide
}

Pu, Minhao; Yang, Lirong; Frandsen, L. H.; Jensen, Jakob Søndergaard; Sigmund, Ole; Ou, Haiyan; Yvind, Kresten; Hvam, Jørn Märcher

Published in:

2010 Conference on (OFC/NFOEC) Optical Fiber Communication (OFC), collocated National Fiber Optic Engineers Conference

Publication date:

2010

Document Version

Publisher's PDF, also known as Version of record

Link back to DTU Orbit

Citation (APA):

Pu, M., Yang, L., Frandsen, L. H., Jensen, J. S., Sigmund, O., Ou, H., Yvind, K., \& Hvam, J. M. (2010). Topology-optimized slow-light couplers for ring-shaped photonic crystal waveguide. In 2010 Conference on (OFC/NFOEC) Optical Fiber Communication (OFC), collocated National Fiber Optic Engineers Conference (pp. 1-3). IEEE.

\section{General rights}

Copyright and moral rights for the publications made accessible in the public portal are retained by the authors and/or other copyright owners and it is a condition of accessing publications that users recognise and abide by the legal requirements associated with these rights.

- Users may download and print one copy of any publication from the public portal for the purpose of private study or research.

- You may not further distribute the material or use it for any profit-making activity or commercial gain

- You may freely distribute the URL identifying the publication in the public portal 


\title{
Topology-Optimized Slow-Light Couplers for Ring-Shaped Photonic Crystal Waveguide
}

\author{
Minhao Pu ${ }^{1}$, Lirong Yang ${ }^{1}$, Lars H. Frandsen ${ }^{2}$, Jakob S. Jensen ${ }^{3}$, Ole Sigmund ${ }^{3}$, Haiyan Ou ${ }^{1}$, \\ Kresten Yvind ${ }^{1}$ and Jørn M. Hvam ${ }^{1}$ \\ ${ }^{1}$ DTU Fotonik, Department of Photonics Engineering, Technical University of Denmark, DK-2800 Lyngby, Denmark \\ ${ }^{2}$ NKT Photonics, Blokken 84, DK-3460 Birkeroed, Denmark \\ ${ }^{3}$ Department of Mechanical Engineering, Technical University of Denmark, DK-2800 Lyngby, Denmark \\ Email: mipu@fotonik.dtu.dk
}

\begin{abstract}
We demonstrate a topology-optimized coupler for a ring-shaped photonic crystal waveguide to improve the coupling of light located in the slow-light regime. An enhancement of the coupling efficiency of up to $2.5 \mathrm{~dB}$ is experimentally demonstrated.

(C)2010 Optical Society of America

OCIS codes: (130.3120) Integrated optics devices; (230.5298) Photonic crystals; (230.7390) Waveguides, planar.
\end{abstract}

\section{Introduction}

Silicon photonic crystal components are widely investigated for use in integrated optics for a broad range of applications. Recently, a photonic crystal with ring-shaped holes was proposed by Kurt et al. [1] to obtain a complete photonic band gap. The structure has also been applied for dispersion engineering to achieve a flat-band slow-light waveguide [2]. Moreover, this type of photonic crystal structure is believed to provide high sensitivity in refractive index sensing applications [3, 4]. However, the coupling between access ridge waveguides and ringshaped photonic crystal waveguides ( $\mathrm{RPhCW}$ ) becomes a problem, especially in the slow-light regime due to high impedance mismatch. Säynätjoki et al. [5] have proposed a slow-light coupler for the RPhCW, but shown no experimental results. Here we apply topology optimization (TO) $[6,7,8,10]$ to design a slow-light coupling interface, and experimentally demonstrate a coupling-efficiency improvement of up to $2.5 \mathrm{~dB}$.

\section{Topology optimization and simulation}

The optimization was performed on an RPhCW consisting of a hexagonal lattice (pitch $\Lambda=405 \mathrm{~nm}$ ) of ring-shaped holes which are defined by their outer $\left(R_{o}=152 \mathrm{~nm}\right)$ and inner $\left(R_{i}=76 \mathrm{~nm}\right)$ radii. As shown in Fig. 1(a), the W1 $\mathrm{RPhCW}$, formed by omitting one row of the holes, is conventionally butt-coupled to a ridge waveguide. The waveguide modes of the RPhCW penetrate highly into the cladding of the ring-shaped photonic crystal (RPhC) while the modes of the ridge waveguide are highly confined in the waveguide core as illustrated in Fig. 1(a). Therefore, the large mode mismatch between the $\mathrm{RPhCW}$ and the ridge waveguide makes the coupling inefficient.
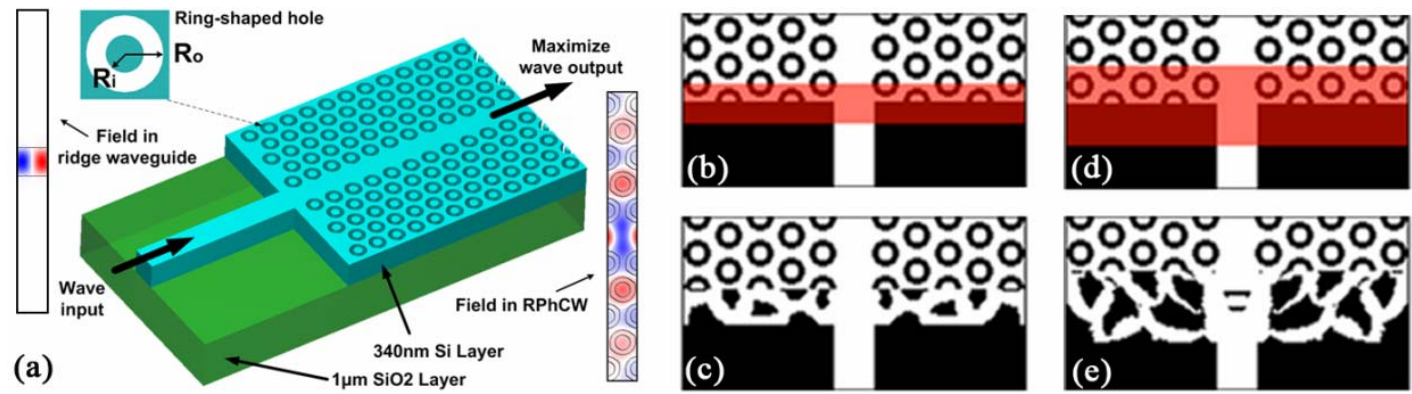

Fig. 1. (a) Schematic diagram of the RPhCW, (b,d) Un-optimized coupling region with different design domains (red shadows) for topology optimization, (c,e) Optimized slow-light couplers for the different design domains, respectively.

The TO modelling of the waveguide is done by solving 2D Helmholtz equations using the finite-element method. Transmission of light at two frequencies within the slow light regime were solved in each iteration and analytical sensitivities were obtained. The Method of Moving Asymptotes (MMA) [9] is used iteratively to generate a new design by modifying the refractive index in each element to maximize the wave output (see Fig. 1(a)). The optimization converges when the change in design is sufficiently small. The optimization is performed within the chosen design domain (see Figs. 1(b) and (d)), which is the vicinity of the interface between the ridge waveguide and the RPhCW. The optimized structures for the two chosen design domains are shown in Figs. 1(c) and (e).

To verify the performance of the TO method, 2D finite-difference time-domain (FDTD) calculations were used to analyze the fields propagating in the RPCW in two regimes: At a wavelength far from the cut-off wavelength (in the fast-light regime, Figs. 2(c) and (d)) and close to the cut-off wavelength (in the slow-light regime, Figs. 2(e) and 
(f)). It is seen that for the un-optimized structure, there is a significant reflection from the edge of the $\mathrm{RPhCW}$ (see Fig. 2(e)) while the reflection is smaller for the short-wavelength light in the fast-light regime (see Fig. 2(c)). Obviously, the slow light suffers more coupling loss. However, there is only little reflection both for fast light and slow light in the optimized structure (see Figs.2 (d) and (f)). Thus, an efficient coupling can be achieved by optimizing the structure.

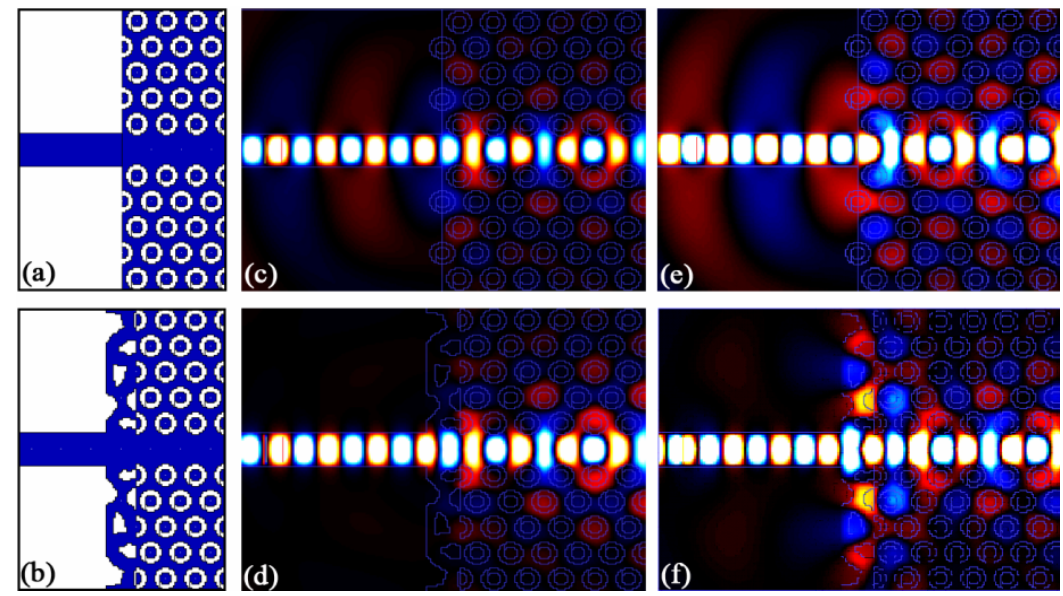

Fig. 2. The un-optimized (a) and optimized (b) coupling structures for the RPhCW, and the corresponding 2D FDTD-calculated field propagations in the fast light regime $(\mathrm{c}, \mathrm{d})$ and slow light regime $(\mathrm{e}, \mathrm{f})$.

Figure 3(a) shows the simulated transmission spectra for the two structures in Figs. 2(a) and (b) by using 3D FDTD calculations. It is noticed that the transmittance of the RPhCW is dramatically improved within a $\sim 50-\mathrm{nm}$ band width by applying TO to the design. The inset of Fig. 3(a) illustrates the coupling improvement in this band width and a maximum coupling enhancement of $2.3 \mathrm{~dB}$ is found in the vicinity of the band edge (the slow light regime). To examine the effect of the air-filling factor, we also performed 2D FDTD calculations for the optimized structure with different ring width $\left(G=R_{o}-R_{i}\right), G=0.16 \Lambda, G=0.19 \Lambda$ and $G=0.22 \Lambda$. Figure $3(\mathrm{~b})$ shows the spectra with the different air-filling factors. It is found that the bandwidth of coupling improvement increases and the bands move to longer wavelengths with decreasing ring width. The maximum coupling enhancement decreases only from $2.4 \mathrm{~dB}$ to $2.1 \mathrm{~dB}$. Therefore, the optimized slow-light coupler is robust and can tolerate small variations of the ring width from the fabrication process.
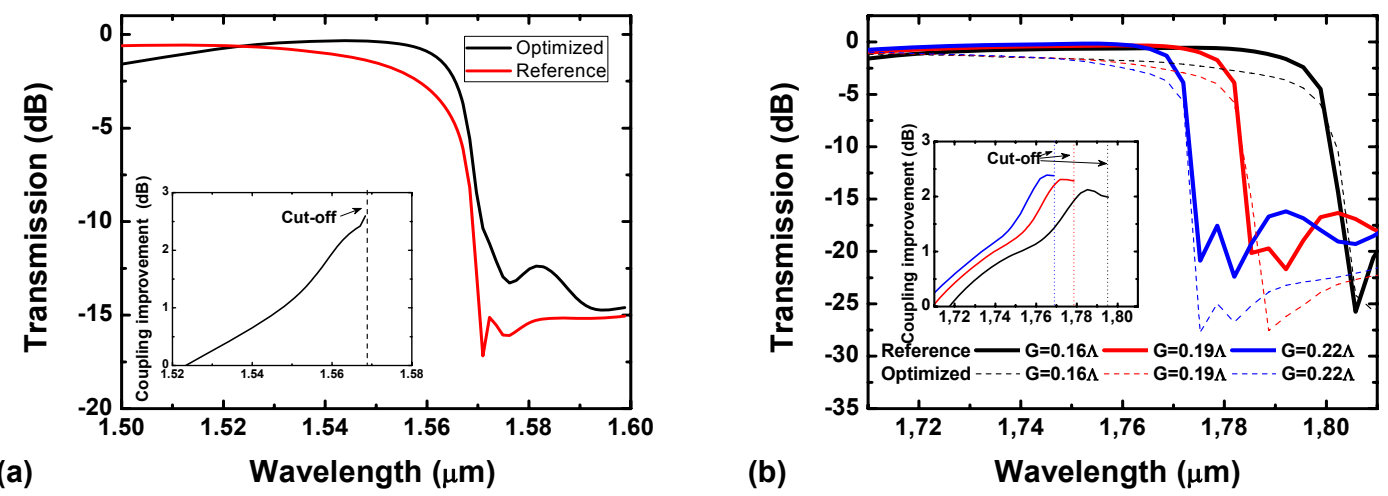

Fig. 3. (a) 3D simulated transmission spectra for the $\mathrm{RPhCW}$, (b) $2 \mathrm{D}$ simulated transmission spectra for the RPhCW with different ring-gap widths, insets are the calculated coupling improvement for the optimized coupler.

\section{Fabrication and measurement}

Two slow-light couplers, shown in Figs. 4(b) and (c), were fabricated and characterized in order to verify the efficiency of the TO method. The samples were fabricated using e-beam lithography (JEOL-JBX9300FS) and inductively-coupled plasma reactive-ion etching to define the RPhCW structures into the $\sim 340$-nm top silicon layer of a silicon-on-insulator wafer. The fabricated RPhCWs are $\sim 5 \mu \mathrm{m}$ long and connected to tapered ridge waveguides to route light to and from the sample facets. An RPhCW with standard coupling region was also fabricated as a reference (see Fig. 4(a)). For each of those structures, the in- and out-coupling regions are designed and fabricated 
identically. Light transmission experiments were performed, where light from a tunable laser source (1520 $1620 \mathrm{~nm}$ ) was launched into the sample and collected by an optical spectral analyzer to record the transmission spectrum. The polarization of the input light was adjusted to the quasi-TE mode with a fiber polarization controller.
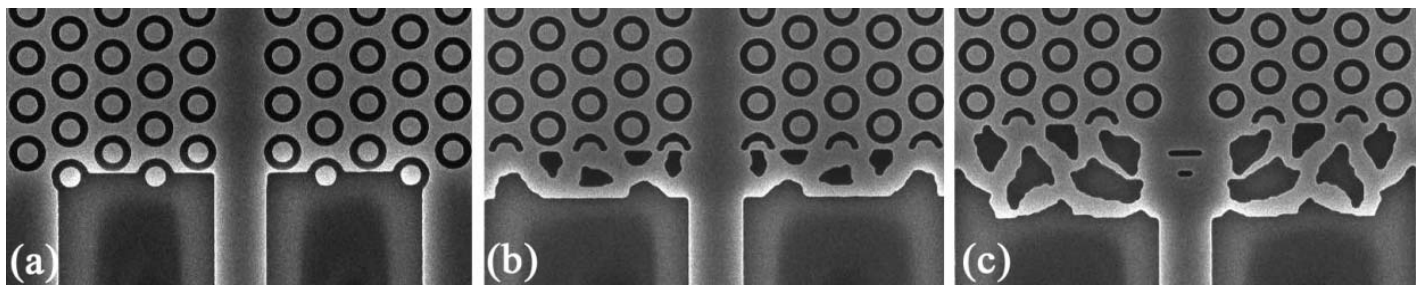

Fig. 4. Scanning electron micrographs of the un-optimized (a) and two optimized $(b, c)$ structures.

The measured transmission spectra are shown in Fig. 5 for the two optimized (blue) coupling interfaces. It is clear that both optimized structures have higher coupling efficiencies near the band cut-off than the reference structure as we expected. Also shown in the figures are the extracted coupling improvements for the two couplers (see insets in Fig. 5). An enhancement in the combined in- and out-coupling of up to $5 \mathrm{~dB}$ is observed in the slow light regime close to the band cut-off of $\sim 1600 \mathrm{~nm}$ for both designs. Thus, the experimental results confirmed the predicted improved coupling performance of $\sim 2.5 \mathrm{~dB}$ per coupling of the topology-optimized slow-light interfaces.
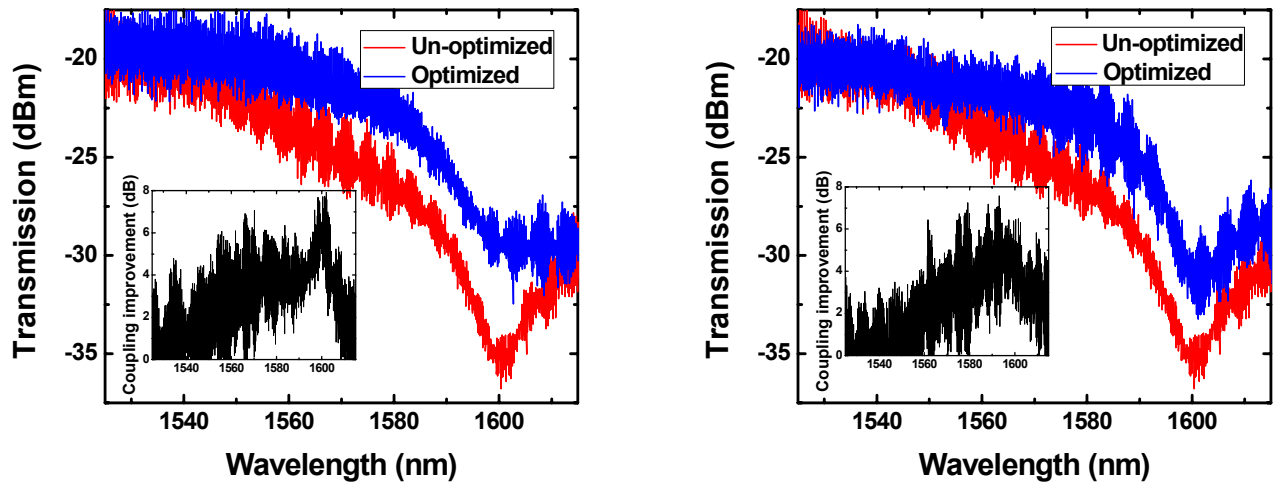

Fig. 5. Measured transmission spectra for two optimized couplers (Left is for Fig. 4(b) and right is for Fig. 4(c)), insets are the extracted coupling improvements for the two couplers.

\section{Conclusion}

The TO method has been used to improve the in- and out-coupling for RPhCW. Two optimized coupling interfaces with different design domains have been fabricated and tested. Up to $2.5 \mathrm{~dB}$ coupling efficiency enhancements per coupling in the slow-light regime were experimentally observed for both designs.

\section{Reference}

[1] H. Kurt and D.S. Citrin, “Annular photonic crystals,” Optics Express, vol. 13, Dec. 2005, pp. 10316-10326.

[2] A. Säynätjoki, M. Mulot, J. Ahopelto, and H. Lipsanen, "Dispersion engineering of photonic crystal waveguides with ring-shaped holes," Optics Express, vol. 15, Jun. 2007, pp. 8323-8328.

[3] A. Säynätjoki, M. Mulot, K. Vynck, D. Cassagne, J. Ahopelto, and H. Lipsanen, "Properties, applications and fabrication of photonic crystals with ring-shaped holes in silicon-on-insulator," Photonics and Nanostructures - Fundamentals and Applications, vol. 6, Apr. 2008 , pp. $42-46$.

[4] M. Pu, L. Liu, L.H. Frandsen, H. Ou, K. Yvind and J.M. Hvam, "Ring-shaped photonic crystal waveguides for refractive index sensing," submitted to OFC 2010 conference.

[5] A. Säynätjoki, K. Vynck, M. Mulot, D. Cassagne, J. Ahopelto, and H. Lipsanen, "Efficient light coupling into a photonic crystal waveguide with flatband slow mode," Photonics and Nanostructures - Fundamentals and Applications, vol. 6, Nov. 2008, pp. 127-133.

[6] M.P. Bendsøe and O. Sigmund, Topology optimization - Theory, Methods and Applications (Springer-Verlag, 2003).

[7] L. Yang, A. Lavrinenko, L.H. Frandsen, P.I. Borel, A. Têtu, and J. Fage-Pedersen, "Topology optimisation of slow light coupling to photonic crystal waveguides.," Electronics Letters, vol. 43, 2007, pp. 923-924.

[8] P. Borel, A. Harp th, L. Frandsen, M. Kristensen, P. Shi, J. Jensen, and O. Sigmund, "Topology optimization and fabrication of photonic crystal structures," Optics Express, vol. 12, May. 2004, pp. 1996-2001.

[9] K.Svanberg, "The method of moving asymptotes: a new method for structural optimization," Int. J. Numer. Meth. Engng. 24, 359-373 (1987) [10] J.S. Jensen and O. Sigmund, "Systematic design of photonic crystal structures using topology optimization: Low-loss waveguide bends," Applied Physics Letters, vol. 84, Mar. 2004, pp. 2022-2024. 